concentration of F.D.P. was $2 \mu \mathrm{g} / \mathrm{ml}$ or more. In these circumstances the diagnosis of a proliferative glomerulonephritis was almost certain. Daily measurement in unspecified proliferative glomerulonephritis, S.L.E., and membranoproliferative glomerulonephritis also provided information relevant to the activity, natural history, and prognosis. In poststreptococcal glomerulonephritis, for example, after a limited period of activity there was abrupt cessation of F.D.P. excretion at the time of clinical recovery. Where clinical evidence of activity persisted large fluctuations of F.D.P. concentration occurred which increased in magnitude in progressive disease and were similar to the cyclical peaks noticed in renal homograft rejection (Clarkson, Morton, and Cash, 1970). This cyclical pattern may provide a clue to the nature of the inflammatory stimulus and presumably either reflects a fluctuating inflammatory activity or periodic attempts by the fibrinolytic mechanisms to degrade intraglomerular fibrin. Against this latter hypothesis, however, was the absence of parallel changes between excreted urokinase and F.D.P.

Finally, and perhaps most significant of all, in proliferative glomerulonephritis the daily estimation of urine F.D.P. may provide a tool which, at minimal inconvenience to the patient, facilitates the continual review of specific therapy (Vermylen, Dotremont, Gaetano, Donati, and Michielsen, 1970; Clarkson, Cash, MacDonald, Fuster, Lambie, and Robson, 1971).

Part of the work was carried out by A.R.C. as a Fellow of the Winston Churchill Memorial Trust of Australia and also as a Research Fellow under a grant from the Scottish Home and Health Department. The Scottish Home and Health Department also provided part of the electron microscope equipment. Financial support was obtained also from the Lawson Tait Memorial Trust and the Scottish Hospital Endowments Research Trust.

Thanks are due to Dr. R. A. Cumming, Director of the SouthEast Scotland Regional Blood Transfusion Centre, for his continued support, to Dr. D. S. Pepper for assistance with the fractionation studies, and to Mr. J. Barclay, Mrs. G. Barron, Mr. D. Hunter, and Mr. W. Shade for technical help.

\section{References}

Baldwin, D. S., Lowenstein, J., Rothfield, N. F., Gallo, G., and McCluskey, R. T. (1970). Annals of Internal Medicine, 73, 929 Cameron, J. S., Glasgow, E. F., Ogg, C. S., and White, R. H. R. (1970).

Clarkson, et al. (1971). Second Congress of International Society for Thrombosis and Haemostasis, Oslo, Abstract, p. 112.

Clarkson, A. R., MacDonald, M. K., Fuster, V., Cash, J. D., and Robson, J. S. (1970). Quarterly fournal of Medicine, 39, 585 .

Clarkson, A. R., Morton, J. B., and Cash, J. D. (1970). Lancet, 2, 1220. Colman, R. W., Braun, W. E., Busch, G. J., Dammin, G. J., and Merrill,

Das, P. C. (1970). Fournal of Clinical Pathology, 23, 149.

Hardwicke, J., and Squire, J. R. (1955). Clinical Science, 14, 509.

Herdman, R. C., et al. (1970). American Fournal of Diseases of Childhood,

119, 27.
Humair, L., Potter, E. V., and Kwaan, H. C. (1969a). Fournal of Laboratory and Clinical Medicine, 74, 60.

Humair, L., Potter, E. V., and Kwaan, H. C. (1969b). Fournal of Laboratory

and Clinical Medicine, 74, 72.
Kincaid-Smith, P., Laver, M. C., and Fairley, K. F. (1970). Medical Fournal of Australia, 1, 145.

Kincaid-Smith, P., Saker, B. M., and Fairley, K. F. (1968). Lancet, 2, 1360. MacDonald, M. K., Lambie, A. T., and Robson, J. S. (1959). Scottish Medical fournal, 4, 415.

MacLean, P. R., and Robson, J. S. (1967). Lancet, 1, 539

Marder, V. J., Shulman, N. R., and Carroll, W. R. (1969). fournal of Biological Chemistry, 244, 2111.

Merskey, C., Johnson, A. J., Kleiner, G. J., and Wohl, H. (1967). British Fournal of Hacmatology, 13, 528.

Merskey, C., Kleiner, G. J., and Johnson, A. J. (1966). Blood, 28, 1.

Muehrcke, R. C., Kark, R. M., Pirani, C. L., and Pollak, V. E. (1957) Medicine, 36, 1.

Pollak, V. E., Rosen, S., Pirani, C. L., Muehrcke, R. C., and Kark, R. M. (1968). Annals of Internal Medicine, 69, 1171.

Ruckley, C. V., et al. (1970). British Medical fournal, 4, 395.

Steihm, C. R., and Trygstadt, C. W. (1969). American fournal of Medicine, 46, 774 .

Vassalli, P., and McCluskey, R. T. (1965). American fournal of Medicine,

Vassalli, P., Simon, G., and Rouiller, C. (1963). American fournal of Patho$\log y, 43,579$.

Vermylen, J., Dotremont, G., Gaetano, G. de, Donati, M. B., and Michielsen, P. (1970). European fournal of Clinical and Biological Research, $15,979$.

\title{
Evaluation of Trimethoprim-sulphamethoxazole Compound in Treatment of Salmonella Infections
}

\author{
A. M. GEDDES, R. FOTHERGILL, J. A. D. GOODALL， P. R. DORKEN
}

British Medical fournal, 1971, 3, 451-454

\section{Summary}

Fifty patients suffering from infections caused by various salmonella species were treated with trimethoprimsulphamethoxazole compound. Twenty-three had enteric fever and two were biliary carriers of Salmonella typhi. The other 25 suffered from infections caused by salmonella species other than $S$. typhi or $S$. paratyphi $B$. Twenty-one of the patients with enteric fever responded clinically to the drug, one failed treatment, and one died. Two patients suffering from typhoid fever relapsed and three temporarily excreted $S$. typhi in stools following

East Birmingham Hospital, Birmingham 9

A. M. GEDDES, M.R.C.P.ED., Consultant Physician

R. FOTHERGILL, M.B., Consultant Physician

J. A. D. GOODALL, M.R.C.P., Senior Registrar

P. R. DORKEN, M.B., Formerly Registrar treatment. One of the typhoid carriers was successfully treated. All patients with infections caused by salmonella species other than $S$. typhi or $S$. paratyphi $B$ responded to treatment but 17 continued to excrete the organism in their stools after the course of trimethoprim-sulphamethoxazole compound. Four patients developed rashes during therapy and two became anaemic.

\section{Introduction}

Chloramphenicol has been the drug of choice for the treatment of typhoid fever for over 20 years. However, the rare but serious side effect of aplastic anaemia and the significant incidence of relapse and chronic carrier state following treatment of typhoid with chloramphenicol has led to a search for a safer and more effective agent. The emergence of strains of $S$. typhi resistant to chloramphenicol (Agarwal, 1962) has added a further stimulus to this quest. In vitro most salmonella species are sensitive to ampicillin (Garrod and O'Grady, 1968). However, enteric fever responds less rapidly to ampicillin than to 
chloramphenicol (Geddes and Murdoch, 1964), though ampicillin is a useful antibiotic for the treatment of chronic carriers of $S$. typhi (Christie, 1964). There is little evidence that antibiotics influence the course of non-invasive salmonella infections and indeed they may prolong faecal carriage of the organisms (Lancet, 1970). The successful treatment of enteric fever with trimethoprim-sulphamethoxazole compound has recently been reported from several countries (Akinkugbe et al., 1968; Pugsley et al., 1969; Farid et al., 1970; Kamat, 1970). The present study was set up to evaluate this compound in the treatment of infections caused by a variety of salmonella species.

\section{Patients and Methods}

Fifty patients suffering from salmonella infections have been treated with trimethoprim-sulphamethoxazole compound. Twenty-five had infections caused by $S$. typhi or $S$. paratyphi $B$ (group 1) and 25 (group 2) presented with acute gastroenteritis caused by other salmonella species ( $S$. panama $7, S$. typhimurium $4, S$. enteritidis $3, S$. stanley $3, S$. derby $2, S$. bredeney $2, S$. virchow $1, S$. heidelberg $1, S$. anatum $1, S$. dublin 1$)$.

\section{GROUP 1}

Of the 25 patients in this group 23 were admitted to hospital suffering from enteric fever-14 presented with a first episode of typhoid fever, 4 had paratyphoid fever, and 5 had acute relapses of typhoid fever. The other two patients in this group were biliary carriers of $S$. typhi. Four patients with enteric fever (including two of the relapses) were judged to be only mildly ill, 15 were moderately ill, and four were severely affected by the disease. The typhoid carriers were asymptomatic. There were six children aged under 10 years, six adolescents, and 13 adults. One patient suffering from paratyphoid fever had possible endocarditis (previously undiagnosed aortic incompetence and splinter haemorrhages under the finger-nails); another with a relapse of typhoid fever developed an empyema of the left pleural cavity.

Twenty patients had positive blood cultures immediately before starting treatment (Table I). All $S$. typhi and $S$. paratyphi $B$ isolates were sensitive to a $25-\mu \mathrm{g}$ disc of sulphamethoxazole: trimethoprim (20:1). The drug was given to adults and older children in tablet form, each tablet containing $80 \mathrm{mg}$ of trimethoprim and $400 \mathrm{mg}$ of sulphamethoxazole. Adult patients were given two tablets every six hours for 14 days, apart from the two typhoid carriers who were treated with two tablets three times a day for four weeks and the man with possible endocarditis who received the compound for six weeks. Children received a suitably reduced dose, which was administered as a suspension to small infants. During treatment all patients were carefully observed for untoward side effects of the drug and tests of hepatic and renal function together with full blood counts were performed. Following treatment full haematology was repeated and six stool and urine specimens were taken, if possible at intervals of 48 hours, for culture before the patient was discharged from hospital. After discharge patients were followed up at home by the appropriate public health department who obtained further stool specimens.

TABLE I-Group 1. Source of Organism

\begin{tabular}{l|c|c|c|c|c}
\hline & Blood & Blood and Stool & Stool & Stool and Urine & Empyema \\
\hline S. Typhi & 11 & 6 & 2 & 1 & 1 \\
S. Paratyphi B & 2 & 1 & 0 & 1 & 0 \\
\hline
\end{tabular}

GROUP 2

The 25 patients in this group comprised 7 children, 4 adolescents, and 14 adults. All presented with diarrhoea and vomiting of acute onset, associated in most cases with abdominal pain. Thirteen had only minor systemic upset, nine were moderately ill, and three were severely affected with pronounced dehydration. The infecting organism was cultured from the stools of all 25 patients and from the blood of three. All salmonellae were sensitive to a $25-\mu \mathrm{g}$ disc of trimethoprim-sulphamethoxazole. Adult patients were given two tablets of trimethoprim-sulphamethoxazole three times a day for seven days, while children received a reduced dose. Infants were treated with a suspension of the drug. Severely and moderately ill patients were treated before the diagnosis had been confirmed by isolation of the infecting organism, but in less severely affected cases treatment was not started until a positive stool culture was obtained. Full blood counts were carried out during treatment. Three stools were cultured on successive days following the course of treatment and most patients had at least one specimen taken for culture after discharge from hospital.

\section{Results}

GROUP 1

Twenty-one of the 23 patients suffering from enteric fever responded clinically to trimethoprim-sulphamethoxazole. The duration of fever after starting treatment varied from 1 to 14 days, with a mean of $4 \cdot 7$ days. Acute symptoms and toxaemia subsided in most patients within three days of starting treatment but in four patients they persisted for four days. One severely ill patient failed to respond to treatment. She was a 26 -year-old woman who remained febrile and toxic six days after starting treatment though blood culture at this stage was sterile. Treatment was changed to chloramphenicol with satisfactory response. A 25-year-old Pakistani man died suddenly three days after starting trimethoprim-sulphamethoxazole. He had recently arrived in the United Kingdom and the duration of his illness was uncertain. On admission he was toxic, febrile, and slightly disorientated, but abdominal examination was negative and there was no evidence of malnutrition. S. typhi sensitive to trimethoprim-sulphamethoxazole was cultured from his blood. Three days after starting treatment his general condition rapidly deteriorated, he developed abdominal distention and "coffee-ground" vomiting and died suddenly. At necropsy there was no evidence of perforation of the small bowel or of gastrointestinal haemorrhage. The liver and spleen showed focal necrosis characteristic of typhoid fever.

Two patients who initially responded to trimethoprimsulphamethoxazole relapsed within two weeks of the drug being discontinued. The first was a 39-year-old West Indian man who had previously been treated for typhoid fever with chloramphenicol. He developed an empyema during the course of the relapse and $S$. typhi was cultured from the pleural aspirate. He responded well to trimethoprim-sulphamethoxazole but relapsed again seven days after the drug was stopped. The second patient who relapsed was a 14-year-old boy who developed an acute recurrence of typhoid fever with positive blood culture 14 days after the end of a course of trimethoprimsulphamethoxazole.

Sixteen of the 19 successfully treated patients who did not relapse had negative stool and urine cultures after treatment and at the time of discharge from hospital. The stools of these patients remained negative for salmonellae throughout the follow-up period (Table II). Three patients who responded clinically to trimethoprim-sulphamethoxazole continued to excrete $S$. typhi sensitive to the drug in their stools following

TABLE II-Group 1. Follow-up of Successfully Treated Patients

\begin{tabular}{l|r|r|r|r|r|r|r|r|r|}
\hline Months & 1 & 2 & 3 & 4 & 5 & 10 & 12 & 17 & No follow-up \\
No. of patients & 3 & 6 & 3 & 2 & 1 & 1 & 1 & 1 & 2 \\
\hline
\end{tabular}


the course of treatment. In two of these the organism cleared spontaneously before discharge from hospital. The third patient continued to excrete $S$. typhi six weeks after discharge but subsequent stool cultures were negative.

One of the two typhoid carriers was successfully treated with trimethoprim-sulphamethoxazole, serial stool cultures remaining negative four months after discharge from hospital. The second persistent excreter, a long-standing carrier of $S$. typh $i$ who had a non-functioning gall bladder containing calculi, continued to excrete $S$. typhi, resistant to trimethoprim-sulphamethoxazole, after the four weeks' course of treatment.

\section{GROUP 2}

Acute symptoms were subsiding in 12 patients in this group at the time of bacteriological confirmation of the diagnosis and before therapy had started. A 72-year-old woman was unable to retain the drug because of persistent vomiting and it had to be stopped after two days. Two patients continued to have diarrhoea after the week's course of treatment but both had pre-existing intestinal disease. The other 10 patients in this group, including the three with positive blood cultures, had complete relief of symptoms before the end of the course of trimethoprim-sulphamethoxazole.

Eight patients had negative stools immediately after the course of treatment and subsequent cultures taken at home were sterile. Faecal excretion of salmonellae persisted in the remaining 17 patients at the time of their discharge from hospital. Thirteen of these had further stool cultures taken and 12 were found to be negative. The thirteenth patient continued to excrete $S$. panama in the stools for four months after going home but three consecutive stool cultures were then obtained which were negative for salmonellae.

\section{Side Effects}

\section{SKIN RASH}

Four patients developed maculopapular skin rashes while receiving trimethoprim-sulphamethoxazole. In one case the rash, which developed on the eighth day of treatment, was extensive and associated with fever and systemic upset.

\section{HAEMATOLOGICAL}

In two patients there was a fall in haemoglobin $(\mathrm{Hb})$ during or immediately after a course of trimethoprim-sulphamethoxazole. The first was an English woman aged 22 being treated for a second relapse of typhoid fever. On the day before starting the drug the $\mathrm{Hb}$ was $10.8 \mathrm{~g} / 100 \mathrm{ml}$, with a mean corpuscular haemoglobin concentration (M.C.H.C.) of $32 \%$ and packed cell volume (P.C.V.) of $34 \%$. Blood urea at this stage was $17 \mathrm{mg} / 100 \mathrm{ml}$. Five days later the $\mathrm{Hb}$ was $10.0 \mathrm{~g} / 100 \mathrm{ml}$ and on the fourteenth day of treatment it had fallen to $8.8 \mathrm{~g} / 100 \mathrm{ml}$, with an M.C.H.C. of $35 \%$ and macrocytic red blood cells. Serum bilirubin was less than $1 \mathrm{mg} / 100 \mathrm{ml}$ and the urine did not contain urobilinogen. There was no evidence of gastrointestinal haemorrhage. Serum folic acid, three days after stopping treatment was $4.5 \mathrm{ng} / \mathrm{ml}$ and serum iron was $150 \mu \mathrm{g} / 100 \mathrm{ml}$. The patient was given folic acid and the haemoglobin rose to $13.2 \mathrm{~g} / 100 \mathrm{ml}$.

The second patient who developed anaemia was a 70-year-old woman who was admitted with gastroenteritis caused by S. typhimurium and associated with severe dehydration. Blood urea on admission was $234 \mathrm{mg} / 100 \mathrm{ml}$, falling to $38 \mathrm{mg} / 100 \mathrm{ml}$ with rehydration. At this point, with the patient fully hydrated and six days after starting streatment, $\mathrm{Hb}$ was $14 \mathrm{~g} / 100 \mathrm{ml}$, with a P.C.V. of $39 \%$ and two days later was $14.2 \mathrm{~g} / 100 \mathrm{ml}$. White blood count was $5,600 / \mathrm{mm}^{3}$. Seven days after the end of trimethoprim-sulphamethoxazole therapy the $\mathrm{Hb}$ had fallen to $10 \cdot 8 \mathrm{~g} / 100 \mathrm{ml}$. It remained at this level four days later when the M.C.H.C. was $35 \%$, serum folic acid $5.5 \mathrm{ng} / \mathrm{ml}$, and reticulocyte count $3^{\circ}{ }_{\mathrm{o}}$. Serum bilirubin was less than $1 \mathrm{mg} / 100 \mathrm{ml}$, and there was no urobilinogenuria or evidence of bleeding from the gastrointestinal tract. Four weeks later the $\mathrm{Hb}$ had risen spontaneously to $13 \cdot 1 \mathrm{~g} / 100 \mathrm{ml}$.

\section{Discussion}

The results of treatment with trimethoprim-sulphamethoxazole of patients suffering from enteric fever have recently been reported (Akinkugbe et al., 1968; Pugsley et al., 1969; Farid et al., 1970; Kamat, 1970). A total of 244 patients were treated in four different countries without any deaths or untoward side effects and with only one failure (Pugsley et al., 1969). In the present series of 23 patients with enteric fever one failed to respond to trimethoprim-sulphamethoxazole, another died, and two relapsed within two weeks of stopping the drug. Three patients, though responding clinically, continued to excrete $S$. typhi in stools following the course of treatment but none became persistent excretors of the organism. In the five years before this study 53 consecutive cases of typhoid fever had been treated with chloramphenicol in this department without any deaths. The mean duration of fever in these patients after starting treatment with chloramphenicol was 5 days compared with 4.7 days in the present series treated with trimethoprimsulphamethoxazole.

Faecal excretion of $S$. typhi resistant to trimethoprimsulphamethoxazole persisted following treatment in one of the two typhoid carriers while the other remained clear at the time of writing though the follow-up period of four months is still relatively short (Christie, 1969). Brodie et al. (1970) was able to cure only one out of four typhoid carriers with trimethoprimsulphamethoxazole.

Members of the Association for the Study of Infectious Disease compared the efficacy of neomycin and an inert substance in the treatment of non-invasive salmonella infections (Joint Project, 1970). They found no difference in either the duration of gastrointestinal symptoms or the salmonella clearance rates in the two groups. In the present study acute symptoms had virtually subsided in half of the patients with noninvasive salmonella infections before a bacteriological diagnosis had been made and previous to treatment being started. Symptoms were, however, rapidly relieved in acutely ill patients with positive blood cultures. Two-thirds of the patients with infections caused by salmonellae other than $S$. typhi and $S$. paratyphi $B$ continued to excrete the infecting organisms in their stools following treatment, adding weight to the argument that chemotherapeutic agents are not indicated in the management of non-invasive salmonellosis (Lancet, 1970).

Trimethoprim is an inhibitor of dihyrofolate reductase, the enzyme necessary for the conversion of dihydrofolic acid (folic acid) to tetrahydrofolic acid (folinic acid). It has 10,000 times more activity against bacterial than against mammalian dihydrofolate reductase. In high or prolonged dosage, however, it may interfere with human folinic acid formation and thus inhibit red cell production. There have been reports of anaemia associated with trimethoprim therapy. Kahn et al. (1968) observed megaloblastic anaemia in one out of 10 elderly patients given $1,000 \mathrm{mg}$ of trimethoprim daily for one month. The affected patient's serum folic acid was normal and the bone marrow and peripheral blood reverted to normal on withdrawing the drug. Jewkes et al. (1970) reported the case of a chronic bronchitic patient who developed a megaloblastic bone marrow while receiving long-term trimethoprim-sulphamethoxazole in a dose of four tablets daily. Serum folic acid and vitamin $\mathbf{B}^{12}$ levels were normal, and the anaemia did not respond to folic acid but did respond to folinic acid. In the present study two patients receiving higher than normal doses of trimethoprimsulphamethoxazole became anaemic during or immediately 
after therapy. Unfortunately, the bone marrow was not examined in either patient, though one had macrocytes in the peripheral blood. Both were suffering from severe infections which could have contributed towards the anaemia.

In summary, this study confirms that trimethoprimsulphamethoxazole compound is effective in the treatment of invasive salmonella infections. However, as with chloramphenicol, relapses and continued excretion of $S$. typhi do occur following the treatment of typhoid fever and caution is advised in patients with severe enteric fever where chloramphenicol may remain the drug of choice.

We thank the Medical Officers of Health of Birmingham, Bromsgrove, Coleshill, Dudley, Stratford-on-Avon, Sutton Coldfield, Walsall, Warley, and West Bromwich for their help with follow-up studies. We are indebted to our laboratory colleagues for their co-operation and to Burroughs Wellcome \& Co. for supplies of Septrin.

\section{References}

Agarwal, S. C. (1962). Bulletin of the World Health Organization, 27, 331 Akinkugbe, O. O., Lewis, E. A., Montefiore, D., and Okubadejo, O. A. (1968). British Mcdical fournal, 3, 721.

Brodie, J., Macqueen, I. A., and Livingstone, D. (1970). British Medical Fournal, 3, 318.

Christie, A. B. (1964). Postgraduate Medical fournal, 40, December Suppl.,

p. 84.
Christie, A. B. (1969). In Infectious Diseases: Epidemiology and Clinical Practice, p. 92. Edinburgh and London, Livingstone.

Farid, Z., ct al. (1970). British Medical fournal, 3, 323.

Garrod, L. P., and O'Grady, F. (1968). In Antibiotic and Chemotherapy, . 75 . Edinburgh and London, Livingstone.

p. 75. Edinburgh and London, Livingstone.
Geddes, A. M., and Murdoch, J.McC. (1964). Postgraduate Medical fournal, 40, December Suppl., p. 81.

Jewkes, R. F., Edwards, M. S., and Grant. B. J. B. (1970). Postgraduate Medical fournal, 46, 723.

Joint Project by Members of the Association for the Study of Infectious Disease (1970). Lancet, 2, 1159.

Kahn, S. B., Fein, S. A., and Brodsky, I. (1968). Clinical Pharmacology and Therapcutics, 9,550 .

Kamat, S. A. (1970). British Medical fournal, 3, 320.

Lancet, 1970, 2, 1169.

Pugsley, D. J., Mwanje, L., Pearson, C., and Blowers, R. (1969). Postgraduate Medical fournal, 45, November Suppl., p. 95.

\title{
Anaesthetic-induced Malignant Hyperpyrexia: A Suggested Method of Treatment
}

\author{
GAISFORD G. HARRISON
}

British Medical fournal, 1971, 3, 454-456

\section{Summary}

Experiments in susceptible Landrace pigs have shown that procaine blocks the initiation of anaesthetic-induced malignant hyperpyrexia by both halothane and succinylcholine. Pretreatment with curare prevents only the trigger action of succinylcholine. In a preliminary study procaine was used to treat the established syndrome in five pigs, two of which survived. On the basis of these findings a treatment regimen can be suggested for patients who develop malignant hyperpyrexia.

\section{Introduction}

Though rare, anaesthetic-induced malignant hyperpyrexia continues to attract attention because of its unpredictability, the frightening mortality in those afflicted (in excess of $70^{\prime \prime}{ }_{11}$ ), the puzzle of its pathogenesis, and the complete lack of rational treatment (British Medical fournal, 1968). There is evidence that the lesion or abnormality responsible for this syndrome lies within muscle (Satnick, 1969; Denborough et al., 1970; Harrison et al., 1970; Isaacs and Barlow, 1970). This knowledge was greatly extended by Kalow et al. (1970) when they reported three fundamental observations made on muscle preparations from human survivors of malignant hyperpyrexia. These were that (1) such muscle was more sensitive to caffeine rigor than that of normal controls, (2) this effect was enhanced by exposure to halothane, and (3) halothane depressed calcium uptake by the sarcoplasmic reticulum of these patients whereas it had no effect on that of normal controls.

Caffeine rigor in muscle due to an enhanced release and depressed rebinding of calcium ions by the sarcoplasmic

\footnotetext{
Department of Anaesthetics, University of Cape Town Medical School, Cape Town, South Africa

GAISFORD G. HARRISON, M.D., F.F.A. R.C.S., Senior Lecturer
}

reticulum (Weber and Herz, 1968; Weber, 1968) has long been known to be blocked by procaine (Feinstein, 1963), an effect due to an action of procaine itself on the reticulum and not procaine caffeine complexing.

An obvious question that must follow from these observations is that if halothane and caffeine produce similar changes in sarcoplasmic reticular function, and in fact enhance each other's action, would not procaine block such action of halothane in the same manner as it is known to block caffeine rigor? (Strobel, 1971). Also, what effect would procaine have on succinylcholine initiation of the syndrome, succinylcholine being with halothane the common initiator of the syndrome? (Wilson et al., 1967; Daniels et al., 1969; Harrison et al., 1969; Britt and Kalow, 1970). Further, what was the common pathway by which both halothane and succinylcholine initiated malignant hyperpyrexia?

The answer to these questions was sought in the following experiments on Landrace pigs, known from halothane prescreening to be susceptible to malignant hyperpyrexia (Harrison et al., 1968, 1969).

\section{Experimental Method}

All experiments were carried out under a standard general anaesthetic consisting of induction of anaesthesia with thiopentone, endotracheal intubation, and maintenance of anaesthesia with nitrous oxide and oxygen with intermittent positivepressure respiration. Under these conditions the influence of pretreatment with tubocurarine and procaine on the initiation of the hyperpyrexic syndrome by halothane and succinylcholine was studied. The drugs were administered in the following combinations and sequences-each sequence forming a separate experiment - the number of times each experiment was repeated is given in parentheses: tubocurarine-halothane (1), tubocurarine-succinylcholine (1), procaine-halothane (6), procaine -succinylcholine (2), and procaine-halothane-succinylcholine (3).

Tubocurarine and succinylcholine were administered as single doses. Procaine was administered as a $0.6 \%$ solution by 